\title{
Digitizing food experience: Food taste perception on digital image and true form using hashtags
}

\author{
Afdallyna Fathiyah Harun', Norhafiza Ruslan², Wan Adilah Wan Adnan², Saiful Izwan Suliman', \\ Juhaida Ismail ${ }^{5}$, Hanif Baharin ${ }^{6}$ \\ ${ }^{1,2,3,4}$ Universiti Teknologi MARA, Shah Alam, Selangor, Malaysia \\ ${ }^{5}$ Universiti Teknologi MARA, Pahang, Kampus Raub, Malaysia \\ ${ }^{6}$ Institute of Visual Informatics, Universiti Kebangsaan Malaysia, Malaysia
}

\section{Article Info}

Article history:

Received Jan 13, 2020

Revised Mar 15, 2020

Accepted Apr 19, 2020

\section{Keywords:}

Digital taste experience

Food experience

Hashtags

User experience

Visual perception

\begin{abstract}
Food experience is now omnipresent with the increased use of social media such as Instagram. Users often share food images or video which is often accompanied with \#hashtags. Readers of the post are required to tap into their visual cognition and perception of what it represents. Little exploration has been done to understand if image can simulate food taste and how similar is the perception after user tasted the food. We were motivated to understand the difference of food taste perception on digital image and its true form by studying user hashtags. We applied the case study approach where we focused on a Malaysian dessert to compare user perception of the cakes' dimension which are appearance, flavour, texture and hedonic. Using Instagram, users were requested to create hashtags that depict their taste perception of the cakes before and after tasting the cake. The hashtags were then analysed using content analysis where we found that the perception on digital image and true form had a degree of difference where many of the initial perception were inaccurate. This implies that visual images may not be able to facilitate accurate food taste perception and would need further technology interactivity to achieve the objective.
\end{abstract}

This is an open access article under the CC BY-SA license.

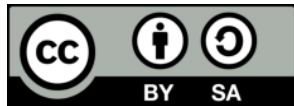

\section{Corresponding Author:}

Afdallyna Fathiyah Harun,

Faculty of Computer and Mathematical Sciences,

Universiti Teknologi MARA Shah Alam Selangor,

40450 Shah Alam, Selangor, Malaysia.

Email: afdallyna@fskm.uitm.edu.my

\section{INTRODUCTION}

Instagram and food are joined at the hip. Making a significant presence since 2010, the platform has one billion monthly active users with over 40 billion photos shared. It is a lucrative partnership where various posts combined can clock in 3.5 billion likes daily and $60 \%$ users would be more likely to discover new products through the platform (statistics from Brandwatch, 2019). Images associated to the hashtag \#foodporn alone has more than 226 million posts at the time of writing illustrating the fact that Instagram users are also keen to share their gastronomical experience with the public over a social media platform [1].

Such statistic exemplifies that users are increasingly exposed to images of food that are both desirable and undesirable, familiar and exotic, as well as tempting and unsavoury. Food posting on Instagram are often presented with images of food and accompanying hashtags with the intention to inform viewers on the food traits as well as to persuade viewers to experience the food for themselves. The latter may not be a prime objective of a posting but nevertheless served as a desirable outcome by many of the Instagrammers. 
The food images shared on such social media is often communicated as a form of celebration and experience sharing [2]. Such celebration is widespread that hashtags such as \#foodie, \#foodporn and \#foodgasm, among others, are evident across the Instagram platform with more than associated 216 million posts in 2017 alone [3]. The motivation to sharing these photos allows the sharing of feelings, memories and experience attributed to the image [4]. It is also to engage conversations and moments of delight among food lovers particularly on the social media platform [5]. Many literatures tend to attribute the behavior of sharing food image via social media as achieving "self-presentational goals", creating an alternate selves for public acceptance/approval/recognition [6-8]. However, these pictures are slowly being perceived as manifesting taste experience with evidence indicating top-brands using Instagram as platform to promote their food and restaurants $[4,9,10]$.

Food taste might differ through expectation [11] as it is influenced by visual impressions of the food and its actual taste [12]. This plays a vital role in determining food acceptance, preference, and choice [13] as users look for visual cues (i.e. food colours, orientation of the food on the plate). According to [14], senses such as vision, emotion, and the environmental circumstance can pre-affect the taste of food. Perception serves as an active and conscious act of seeking out and searching for cues within the stimulus information available to us $[11,15]$. As such, food images can be used as a mediator to elicit taste perception.

However, it begets the question if indeed food images can elicit taste perception fairly where following the food tasting, it matches with the taste perceived from the image seen. The food image might give different taste perception to different individuals due to different expectations [11]. The expectation of how the food would taste is very much influenced by visual impressions of food which can also influence the actual taste [12]. As images are often remarked as "telling a thousand words", it points to a concern if the food image and hashtag descriptors often used in Instagram bring justice to the actual food taste. This study sets to explore this to showcase if indeed image representations of food are reliable in facilitating taste perception. We conducted a performance evaluation which looks into how user perceptions are similar or dissimilar from a visual image to an actual food object and the positive and negative emotional connotations associated with it. This is obtained by conducting content analysis on user created hashtags on an Instagram post depicting Malaysian traditional dessert, the Sarawak Layer Cake

\subsection{Taste perception}

Food provides humans with some of the most universal and rich sensory experiences possible [12]. The perception of tastes usually varies from person to person [16] as everyone would have different sensory experience [17]. This implies that an Instagram image taken by a person to capture a certain taste may be perceived by another person as visualizing different taste altogether. Perception is an active and conscious act of seeking out cues within the stimulus information available to us [11]. Visual information such as colours of food, or background colour can affect the taste of food [14, 18].

Food taste generally comes from the complex combination of smell, texture and taste [19]. However, in an Instagram image, most of the afore mentioned sensory are lacking as users are only provided with visual cues. Even so, visual sensory can be a powerful input provided supporting cues are in place. Food encounter is almost always initiated by visual sensory [20,21] where a visual image with quality attributes could influence users to taste the food. [20] highlighted that the appearance sensory is important in facilitating food acceptance where uses will seek the food's colour, opacity, gloss, visual structure, visual texture and perceived flavour. [20] also determined that colour plays the most critical role in initial judgement of the food which in turn could influence the acceptance or rejection of the food.

A more recent study by [22] further validate the findings in [21]. They found seven image attributes that would influence food acceptance which are (i) attractiveness - appearances and presentation style of the food, (ii) flavour profile, (iii) familiarity, (iv) distinctiveness, (v) cooking method and ingredients, (vi) convenience and price and (vii) health and safety. From the list of attributes, [22] found that attractiveness is the most significant cue. On another note, [23] found that taste, texture, temperature and hedonics features could serve as food presentation profile. He found that people would rely on taste, temperature and texture when describing food and the hedonic features comes from the hedonic experience associated with eating the food.

\section{RESEARCH METHOD}

\subsection{Research design}

The main motivation of our research is understanding users taste perception from a digital image to their taste perception upon actual taste of the food. This would allow us to investigate if indeed the perception are similar or otherwise. To assist in data management, we approached this research with the concept that any food image should comprise manageable constructs that represents food characteristics. 
We postulate that these characteristics are drivers of food perception which users try to apply acuity in predicting what the food would taste like. In addition, the same constructs are used to manifest the taste experience albeit perhaps within different use of terms. Therefore, this study has adapted the food visual dimension model from [20, 22, 23] which is summarised in Table 1.

Table 1. Food visual dimension

\begin{tabular}{llll}
\hline Dimensions & \multicolumn{1}{c}{ Description } & Dimensions & \multicolumn{1}{c}{ Description } \\
\hline Appearance & $\begin{array}{l}\text { Colour, design, and aesthetics of the } \\
\text { food (i.e. description of beauty/ugly) }\end{array}$ & Texture & $\begin{array}{l}\text { Composition (i.e. the end results of the mixture blend), } \\
\text { integration/disintegration (i.e. the crumbly or firm nature } \\
\text { of the cake), ingredient (i.e. description of the texture } \\
\text { based on the ingredients used) }\end{array}$ \\
Flavour & $\begin{array}{l}\text { Taste (i.e. sweet, sour) and sensation } \\
\text { (i.e. tasty, delicious) }\end{array}$ & Hedonic & The feelings of pleasure or displeasure towards the food \\
\hline
\end{tabular}

From the onset, it must be acknowledged that studies from [20, 22, 23] have indeed motioned more constructs on food description. However, we have limited the constructs into the above four as it correlates with the food sample chosen for our study. This is further explained in Section 2.2. To remain within the study context of understanding similarity of taste perception between a food's digital image and its true form, we provided the food subject in both digital image and true form to the study participants. Regardless of how the cakes were presented, we believe that both representations would exemplify the attributes of 'appearance', 'flavour' and 'texture' dimensions of the food which would then interact with users' physiological, behavioural, and cognitive factors to exert influence on user taste perception. This interaction would then affect users' 'hedonic' response of which they may feel an overall pleasure or displeasure towards the food. We also opine that the taste perception from viewing the cake's digital image and tasting its true form would be similar.

\subsection{Food selection}

The focus of our food investigation is Kek Lapis Sarawak or Sarawak Layer Cake. It is known as a popular local dessert from the Malaysian Sarawak state. It is widely promoted in Sarawak Tourism website as well as regarded as one of the must have take-home souvenier for visitors [24]. The cakes are mostly known for its intricate layering designs and different flavour options which are typically sourly sweet and fragrant. However, the more modern variant would have chocolate, cheese and fruity flavours. For our study, we have chosen three types of Sarawak Layer Cakes. The variety chosen were identified as top selling items among Sarawak Layer Cake sellers. These three cakes also allowed the facilitation to elicit dimensions as per Table 1 due to the different colours, flavours and textural appearance of each cake. A summary of the selected cakes can be seen in Table 2 .

Table 2. Sarawak layer cake variety

\begin{tabular}{|c|c|c|c|c|c|}
\hline $\begin{array}{c}\text { Sarawak Layer } \\
\text { Cake }\end{array}$ & Description & $\begin{array}{c}\text { Sarawak Layer } \\
\text { Cake }\end{array}$ & Description & $\begin{array}{c}\text { Sarawak Layer } \\
\text { Cake }\end{array}$ & Description \\
\hline & $\begin{array}{l}\text { Cake 1: Masam Manis } \\
\text { Green, yellow and } \\
\text { brown layers with } \\
\text { sweet sourly taste }\end{array}$ & 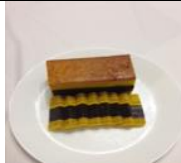 & $\begin{array}{c}\text { Cake 2: Idola Brown } \\
\text { and yellow layers with } \\
\text { chocolatey taste }\end{array}$ & 918 & $\begin{array}{l}\text { Cake 3: Swissroll } \\
\text { Masam Manis } \\
\text { Red, yellow and green } \\
\text { zig-zag layers with } \\
\text { sweet sourly taste }\end{array}$ \\
\hline
\end{tabular}

Sarawak Layer Cakes will generally maintain its taste when kept in room temperature within three days best. After the period, the quality would degrade. Although the cake could be refrigerated for longer shelf-life, the cake would harden affecting its genuine texture representation. In consideration of this, the cakes were used in the following state:

- $\quad$ Cakes in digital image form

The cakes were presented in both loaf and sliced form. The cakes were thinly sliced to highlight the intricate layering of the cakes. Images of the cake was taken using iPhone 5 model immediately after it was thinly sliced to capture its best texture state. We then chose the best picture from all samples taken for each of 
the cake types where the selected sample can be seen in Table 2. Each of the cake images were uploaded into a dummy Instagram account which was created for the purpose of this study.

\section{- $\quad$ Cakes in true form}

The cakes were presented in both loaf and sliced form and served on a white plate. The cakes were thinly sliced to highlight the intricate layering of the cakes and this was done just before the study took place with the users. This means, for each user tasting session, new cakes were used as each of the study took place on different days. The setup for the cake tasting can be seen in Figure 1.

For both cake representations, the cakes were arranged on a white round plate as [18] found that background colour could influence flavour perception (see Figure 1). Moreover, [18] suggested that desserts are more suited to be served on white plating, with white background, placed on a table covered with white tablecloth within a natural lighting. We also set the phone camera into a normal setting without any use of special effects as to reduce image manipulation. Moreover, both formats of representations were alike as to eliminate any form of bias as well as to maintain focus on the cake rather than serving designs.

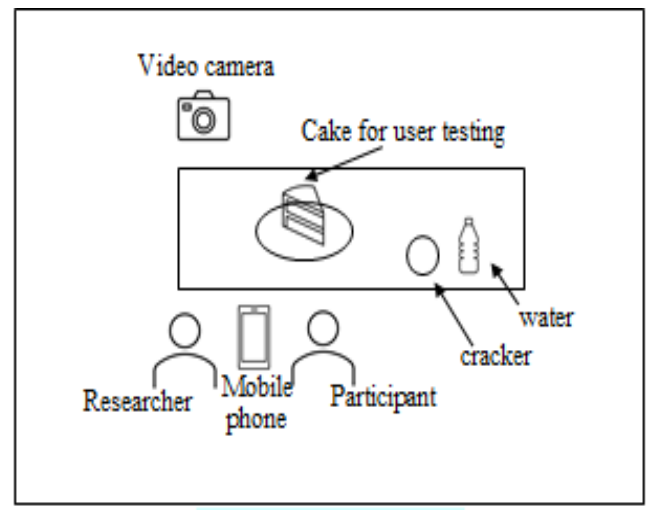

Figure 1. Study setup

In addition to highlighting the intricate layering of the cakes, the cakes were also thinly sliced due to the cultural practice in serving the dessert. In our interview with several elderlies, Sarawak Layer Cakes were considered a novelty and only served during special occasions or festivities. They also added that to ensure many people could have helpings of the cakes as well as due to economic reasons, the cakes were often thinly sliced when served.

\subsection{Participants}

We recruited 10 participants where invitation was made to work colleagues of the second author. They then helped to forward the invitation among their circle of friends until we have managed to get 10 participants in total.

\subsection{Procedure}

We emulated the procedure based on a pilot study we have conducted with a different group of users described here [25]. As our study focused on understanding image attributes significant to taste experience on the Instagram platform, we have created a dummy Instagram account. The account was set as private account, did not follow any other Instagram users and did not allow anyone to follow the dummy account as to avoid any external data input beyond our control. We have set a scenario where the participants played the role of the dummy Instagram account owner. As owner, they must create hashtags to the three cake images displayed on the account screen. This required us to record all hashtags entries and delete them after each participant session ends as to enable the enactment of "Instagram account owner" for each user study. The dummy account was then deleted after the course of study ends. Each of the cake image was displayed separately where after participants have completed creating the hashtags for a particular cake image, they will be shown the next cake image until all three cakes have their own hashtag entries.

This activity is then followed with cake tasting. In this activity, participants were presented with the three types of Sarawak Layer Cakes, one at a time. For each of the cake, users were required to taste it, take a picture of the cake in any form they like as well as create hashtags into the dummy Instagram account. This was alternated with cleansing the palate with a glass of water and water cracker biscuits before user 
could proceed to repeat the process with the next cake until all three cakes were tasted. The palate cleansing was necessary as to ensure the taste of the previous cake would not affect the taste perception [26] on the next cake. Moreover, research by [18] found that water cracker biscuits could cleanse the palate from all flavours including sweet, bitter, fatty, astringent, hot/spicy, cooling and non-lingering. The hashtags created for both digital and true cake representation were regarded as users' visual perception of the cakes in their own words. One of the authors acted as the facilitator by sitting next to the participant as the study progressed. The model of mobile phone used throughout the study was the iPhone 5 model where it was used by the participants to view the cake image, take pictures of the cake and create hashtags. The study took place one user at a time of which each session lasted in average of 15 minutes.

During the study, a video camera was used to record the conversation and participants' expressions. The study flowchart is depicted in Figure 2. Each session would comprise viewing the cakes' digital image and tasting the cakes' true form. We handled each session with one user at a time to avoid users being influenced by other users should the study be conducted in a group. This means, we had 10 user session in collecting the required data. Before each of the session took place, we first explained the purpose and the procedures of the data collection to the participants. Then, as depicted in Figure 2, each participant was presented with pictures of each of the three Sarawak Layer Cakes through the Instagram dummy account. Subsequently, participants were asked to create hashtags based on leading questions of "how would you describe the cake in terms of appearance, flavour and texture" as well as "how does the look of the cake make you feel?". The purpose of the questions is to make sure participants do not create meaningless hashtags. After participants have registered the hashtags based on cakes' digital image, participants were requested to taste each of the three cakes, take pictures of the cakes and create hashtags.

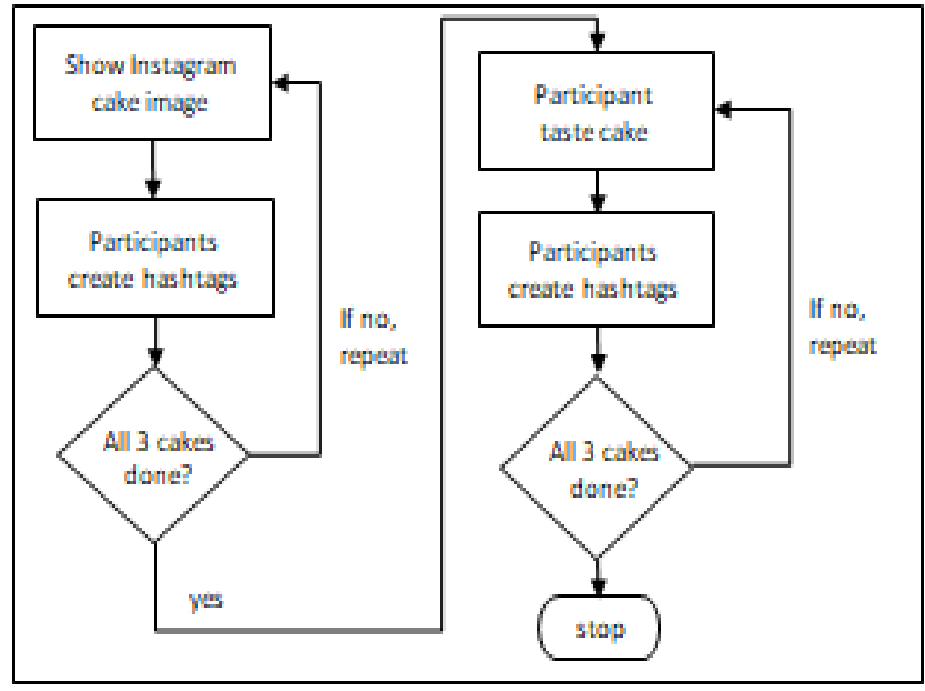

Figure 2. Study flowchart setup

\subsection{Data analysis}

Content analysis was used to examine the constructs of food visual dimensions in user-created hashtags for both digital image and true cake representations into the food dimension context it represents (as per Table 1) as well as the nuances (i.e. positive sounding and negative sounding hashtags). These constructs were then quantified to tabulate the frequency of appearance. Presentation wise, the hashtags were translated into English words as the original hashtags mostly used Malay words. It must be noted however that the content analysis was done on the original hashtags as it captured users' original perception. This did not serve a problem to the researchers as Malay language is their native language.

\section{RESULTS AND DISCUSSION}

\subsection{Profile of the participants}

A total of ten users participated in this study. Interestingly, none of them have travelled to Sarawak before nor have they tasted the three Sarawak Layer Cakes used in this study. This we believe presented an opportunity for genuine cakes flavour perception by the users. 


\subsection{Study a: user hashtags on cake digital image}

Table 3, 4 and 5 presents the hashtags created by users by looking at the digital image of each of the Sarawak Layer Cake. Hashtags in Malay language have been translated into English for the purpose of this paper's presentation. To meet with the requirements of the paper format, we will only display selected results for each food visual dimension to give an understanding on the nature of user input. Additionally, repetitive hashtags were also omitted with the number brackets indicating the number of frequencies. Based on the ten interviews, a total of 184 hashtags were compiled for all three cakes. Distribution of hashtags for each of the cakes were, Cake 1: 66 hashtags, Cake 2: 58 hashtags and Cake 3: 60 hashtags. The hashtags had both positive and negative nuance.

Table 3. User hashtags for cake 1 digital image

\begin{tabular}{|c|c|c|}
\hline $\begin{array}{c}\text { Food Visual } \\
\text { Dimension }\end{array}$ & Sample Hashtags & $\begin{array}{c}\text { Total } \\
\text { Hashtags }\end{array}$ \\
\hline Appearance & $\begin{array}{l}\text { \#appetizingcolours(2), } \\
\text { \#colourful(3), \#fascinating (2), } \\
\text { \#fascinatingcolours(2), } \\
\text { \#layered(2) }\end{array}$ & 21 \\
\hline Taste & $\begin{array}{l}\text { \#butteryscrewpinetaste, \#oily, } \\
\text { \#quitesour, } \quad \text { \#scrumptious(2), } \\
\text { \#sweet(2), } \\
\text { \#tasty }\end{array}$ & 16 \\
\hline Texture & $\begin{array}{l}\text { \#fluffy, \#fluffyandsoft, \#moist, } \\
\text { \#quitedense, } \quad \text { \#soft(6), } \\
\text { \#softanddelicate }\end{array}$ & 11 \\
\hline \multirow[t]{2}{*}{ Hedonic } & $\begin{array}{l}\text { \#appetizingcolours, \#bellyful, } \\
\text { \#justonce, \#Kedahcolours, } \\
\text { \#love, \#onlyoccasionally, } \\
\text { \#savouragain }\end{array}$ & 18 \\
\hline & & 66 \\
\hline
\end{tabular}

Table 4. User hashtags for cake 2 digital image

\begin{tabular}{|c|c|c|}
\hline $\begin{array}{c}\text { Food Visual } \\
\text { Dimension }\end{array}$ & Sample Hashtags & $\begin{array}{c}\text { Total } \\
\text { Hashtags }\end{array}$ \\
\hline Appearance & $\begin{array}{l}\text { \#dislikethecolour(2), } \\
\text { \#disorganized, } \\
\text { \#needmorecolours, \#striking, } \\
\text { \#unappealing(3), } \\
\text { \#yellowchocolate }\end{array}$ & 16 \\
\hline Taste & $\begin{array}{l}\text { \#butterysweet, } \\
\text { \#creamyandsweet, \#maybebitter, } \\
\text { \#quitesour, \#sweet(2), } \\
\text { \#temptingchocolate }\end{array}$ & 12 \\
\hline Texture & $\begin{array}{l}\text { \#densebutmoist, \#maybesoft, } \\
\text { \#soft(2), \#softanddelectable, } \\
\text { \#softandgreasy, \#sticky }\end{array}$ & 7 \\
\hline \multirow[t]{2}{*}{ Hedonic } & $\begin{array}{l}\text { \#appetizing, \#bestasdessert, } \\
\text { \#cringe, } \\
\text { \#justonce,\#typical,\#unsatisfying, }\end{array}$ & 23 \\
\hline & & 58 \\
\hline
\end{tabular}

Table 5. User hashtags for cake 3 digital image

\begin{tabular}{|c|c|c|}
\hline $\begin{array}{c}\text { Food Visual } \\
\text { Dimension }\end{array}$ & Sample Hashtags & $\begin{array}{c}\text { Total } \\
\text { Hashtags }\end{array}$ \\
\hline Appearance & $\begin{array}{l}\text { \#beautiful(2), \#cheerful, } \\
\text { \#colourful(2), } \\
\text { \#looksfascinating, } \\
\text { \#wowfascinating }\end{array}$ & 12 \\
\hline Taste & $\begin{array}{l}\text { \#butterysugarsweet, } \\
\text { \#delectable(2), \#sharp, } \\
\text { \#slightlysweet, \#sweetsour(3) } \\
\text { \#crumblysoft, \#dense, \#fluffy, }\end{array}$ & 11 \\
\hline Texture & $\begin{array}{l}\text { \#softandmoistcake(2), } \\
\text { \#thickbutsoft }\end{array}$ & 11 \\
\hline \multirow[t]{2}{*}{ Hedonic } & $\begin{array}{l}\text { \#delishatnight, \#fancy (2), } \\
\text { \#happy(2), \#wantmore(4), } \\
\text { \#maybejustanotherslice }\end{array}$ & 26 \\
\hline & & 60 \\
\hline
\end{tabular}

a. Appearance

The hashtags for appearance were further categorized into how the cake made an impression through colours $(43 \%)$, design (14\%) and aesthetics (43\%). We found that 'colour'-related hashtags incorporated the word 'colour' or hue description into the hashtags. Hashtags with 'design' attribute looks specifically on the cake structure where participants scrutinized on the cake layers. 'Aesthetics' on the other hand look at the overall appeal of the cake presentation. For Cake 1, the hashtags were inclined towards how the cake appeared appetizing, fascinating and colourful. From Figure 3, Cake 2 received the greatest number of negative hashtags in describing its appearance (i.e. \#disorganized, \#unappealing, \#dislikethecolours) as most users found the colours unattractive and unappealing. Cake 3 on the other hand received hashtags that focused on how the colours are cheerful and reminded them of the rainbow. Overall, it can be perceived that Cake 1 appeared more inviting for the users and vice versa for Cake 2. The findings imply that colour is an important sensory dimension that affects the perceived aesthetics of the food item [22] and ultimately the food acceptance and rejection [20]. 


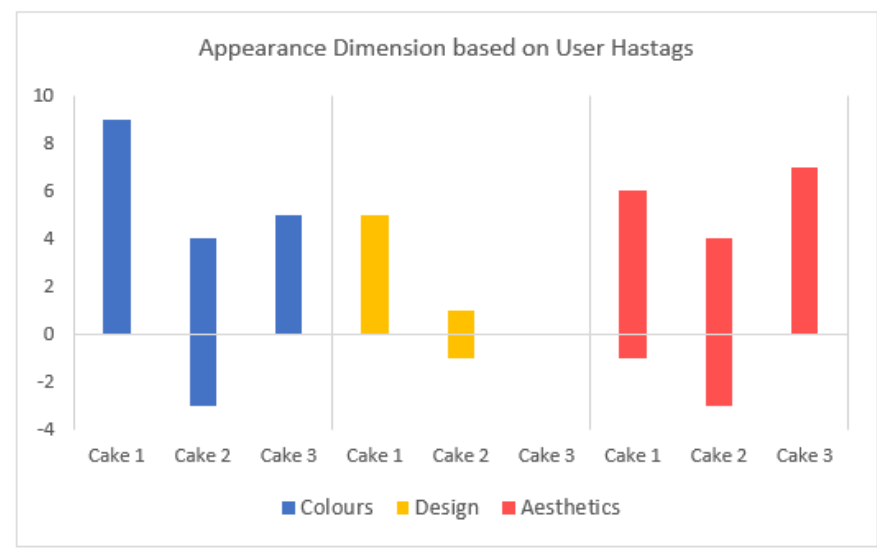

Figure 3. User hashtags on cake appearance based on digital image

\section{b. Flavour}

'Flavour' dimension refers to how users make taste perception (51\%) and its overall sensation (49\%). Figure 4 illustrates the pattern for both attributes for all three cakes. All cakes had hashtags with negative taste attribute description while for sensation, only Cake 2 received negative hashtags. For Cake 1 and Cake 2, there were hashtags describing the sweet and sour taste of the cake. Although an interesting observation, we were not overly surprised as we felt users were able to make the taste perception due to the name of the cakes indicated at the Instagram cake image. Both Cake 1 and Cake 3 have the name Masam Manis which means sweet sour. Many of the users created hashtags that depicted the cake flavours based on the colours they see. We believe the users have a "reference point" to gauge the new food items based on experience even when presented in a foreign setting [22].

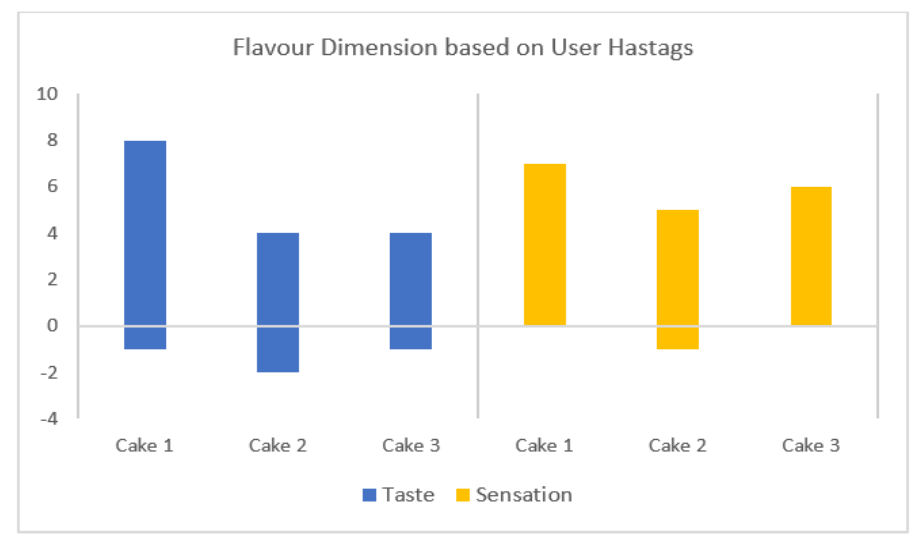

Figure 4. User hashtags on cake flavour based on digital image

c. Texture

Food texture is attributed to the structural elements of the food which is primarily sensed by the feeling of touch. The underlying foundation to the concept is, with a tactile interaction with the cake, one can sense the formation, disintegration, and flow of the food under a force [27]. In the context of our study, it is observed that textures are largely attributed to composition (76\%), integration/disintegration of the cake $(17 \%)$ and ingredient element $(7 \%)$. To further put the attributes in context, hashtags examples for composition include \#soft, \#moist, and \#fluffy. For integration/disintegration, hashtags would be \#dense and \#crumbly. For ingredients-based texture, it is observed that the hashtags are mostly related to the butter and oil ingredient such as having the words oily or greasy. Figure 5 illustrates the pattern of user hashtags for the texture dimension of the three cakes digital images. Most of the hashtags focused on the composition attribute where users largely created positive-sounding hashtags describing the cakes as soft, moist and fluffy. Not many hashtags were created in terms of integration/disintegration as well as ingredient attribute. However, when such hashtags are found, they are largely negative with the former perceiving the cake as dense and the latter as greasy-not a particularly inviting description for a cake. 


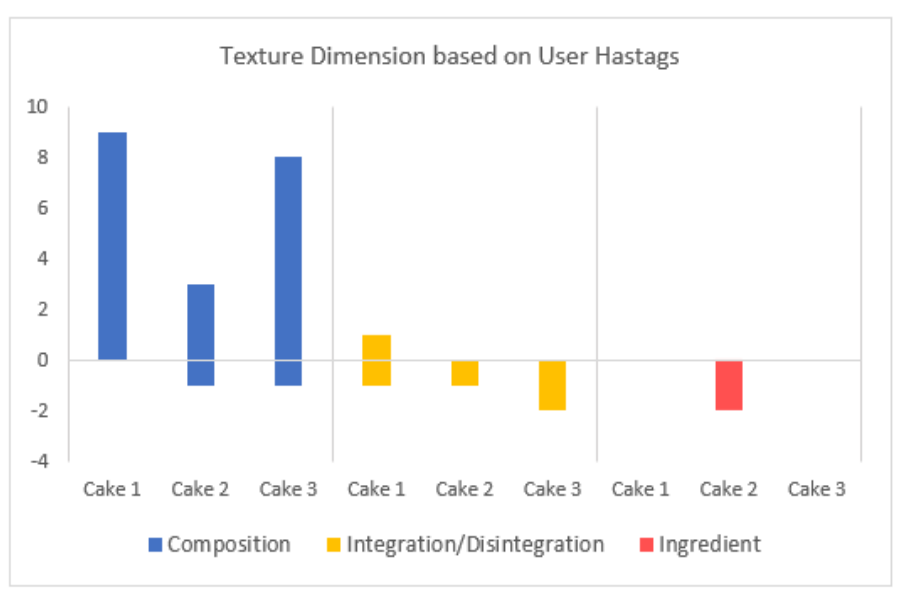

Figure 5. User hashtags on cake texture based on digital image

\section{d. Hedonic}

Hedonic perception towards food is largely on how pleasure/displeasure user feel towards the food object. It would be a collective conclusion made by the user derived from the other food dimensions put into their thoughts before this (which we feel it the case due to the nature of the data collection procedure in our study). All cakes have hashtags with pleasurable hedonic attribute $(67 \%)$ and displeasure hedonic attribute $(33 \%)$. Figure 6 illustrates that Cake 2 has the least number of pleasurable hashtags and the greatest number of unpleasurable hashtags. The opposite was observed for Cake 3. We concluded that this may be due to the overall negative perception to the other dimensions Cake 2 received as discussed in the previous sections. Cake 3 which had an overall pleasing hashtag on the other dimensions (see Figure 3-5) had the most number of pleasurable hashtags with entries implying eagerness to eat and wanting more. This further brings home the point that appearance (predominantly colour) is indeed an important sensory dimension which affects food acceptance and rejection [28].

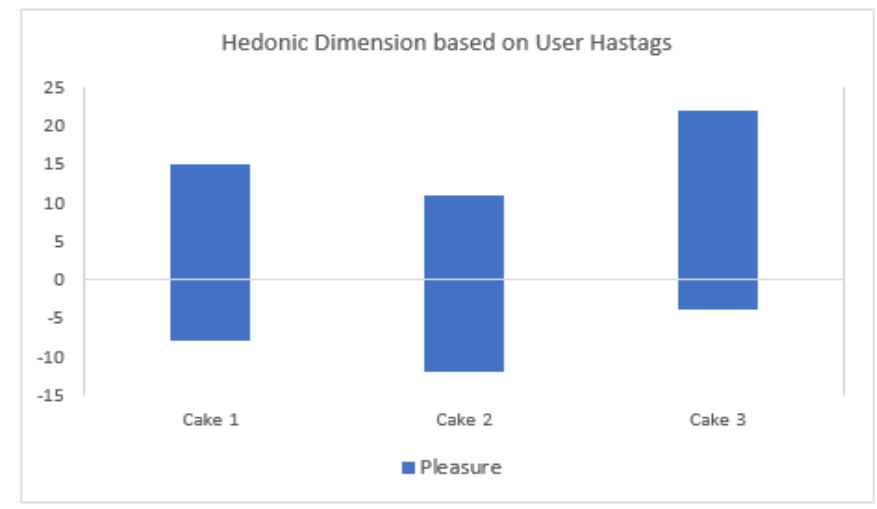

Figure 6. User hashtags on cake hedonic based on digital image

\subsection{Study B: user hashtags on cake true form}

Table 6, Table 7 and Table 8 presents the hashtags created by users after tasting the cakes presented to them. Hashtags in Malay language have been translated into English for the purpose of this paper's presentation. To meet with the requirements of the paper format, we will only display selected results for each food visual dimension to give an understanding on the nature of user input. Additionally, repetitive hashtags were also omitted with the number brackets indicating the number of frequencies. In this study, we observed that users interacted with the cake by pressing and smelling the cakes, having a close look towards the cake design as well as taking a small bite before continuing with a bigger bite (if they find the first bite pleasurable). This behavior gives an early finding that interacting with a digital image would not give users the degree of interactivity that one would have when interacting with a real cake. Nevertheless, we hoped that 
the perception user had by viewing the cakes' digital images would not be far different from the perception they gather after they consumed the cake. However, if it did, it would be a more pleasing experience. This is because, we would not want a picture to simply create a hype but end up disappointing the users after eating them.

Table 6. User hashtags for cake 1 true form

\begin{tabular}{|c|c|c|c|c|c|}
\hline $\begin{array}{c}\text { Food Visual } \\
\text { Dimension }\end{array}$ & Sample Hashtags & $\begin{array}{c}\text { Total } \\
\text { Hashtags } \\
\end{array}$ & $\begin{array}{c}\text { Food Visual } \\
\text { Dimension }\end{array}$ & Sample Hashtags & $\begin{array}{c}\text { Total } \\
\text { Hashtags } \\
\end{array}$ \\
\hline Appearance & $\begin{array}{l}\text { \#captivating, } \\
\text { \#colourmismatchtaste, } \\
\text { \#fascinating(3), } \\
\text { \#fascinatingcolours }(4)\end{array}$ & 15 & Appearance & $\begin{array}{l}\text { \#coloursofmyheart, } \\
\text { \#dislikethecolour(2), } \\
\text { \#disorganized, \#unappealing(3), } \\
\text { \#vibrant }\end{array}$ & 17 \\
\hline Taste & $\begin{array}{l}\text { \#delectable, \#sweetandsour(4), } \\
\text { \#nottoosweetbutdelectable, } \\
\text { \#softanddelectable, \#sour(2), }\end{array}$ & 12 & Taste & $\begin{array}{l}\text { \#chocolaty \#delectable(2), } \\
\text { \#delectablechoc, \#sodelectable(2), } \\
\text { \#sweetbutterychocolate }\end{array}$ & 15 \\
\hline Texture & $\begin{array}{l}\text { \#denseandsoft, \#firmandsoft, } \\
\text { \#lessrefine, \#moistandsoft(2), } \\
\text { \#soft(2), \#softanddelectable }\end{array}$ & 12 & Texture & $\begin{array}{l}\text { \#fluffyandmoist, \#looksdense, } \\
\text { \#nottoosoft, \#soft, \#softandoily, } \\
\text { \#softtexture(2) }\end{array}$ & 11 \\
\hline Hedonic & $\begin{array}{l}\text { \#eatlayerbylayer, \#feelhappy, } \\
\text { \#like(2), \#nomore(2), } \\
\text { \#wantmore(2), \#wanttoeatmore(2) }\end{array}$ & 18 & Hedonic & $\begin{array}{l}\text { \#iwantmore, \#nomore(3), \#repeat, } \\
\text { \#sodelectable, \#tastenotright, } \\
\text { \#toshare, \#unappealing, }\end{array}$ & 21 \\
\hline & & 61 & & & 64 \\
\hline
\end{tabular}

Table 8. User hashtags for cake 3 true form

\begin{tabular}{clc}
\hline $\begin{array}{c}\text { Food Visual } \\
\text { Dimension }\end{array}$ & \multicolumn{1}{c}{ Sample Hashtags } & $\begin{array}{c}\text { Total } \\
\text { Hashtags }\end{array}$ \\
\hline \multirow{3}{*}{ Appearance } & $\begin{array}{l}\text { \#cheerful, \#colourful(2), } \\
\text { \#fascinating(2), } \\
\text { \#fascinatingcolours(3), }\end{array}$ & 23 \\
& \#delectable(2), \#slightlysour(2), & \\
Taste & \#sweetbutdelectable, \\
& \#sweetandsour(4), \#toosweet & 12 \\
Texture & $\begin{array}{l}\text { \#denseandsoft, \#soft, } \\
\text { \#softandmoist(2), \#softandoily, }\end{array}$ & \\
& $\begin{array}{l}\text { \#softtexture } \\
\text { Hedonic }\end{array}$ & \#mustry, \#nogertotry(2), \#more, \\
& \#worthit & 23 \\
& & 67 \\
\hline
\end{tabular}

In presenting our analysis in the proceeding sections, we have used figures to illustrate trends of user hashtags. In each of the figure, there is also a marked line illustrating the number of user hashtags based on digital images of the cakes allowing easier data comparison between Study A and Study B.

a. Appearance

Hashtags for appearance were found attributed to colours (35\%), design (7\%) and aesthetics (58\%). As the perception of appearance is facilitated with the sight sensory, difference between hashtags in Study A and Study B was not expected. If one were to compare the hashtags listed in Table 3-5 and Table 6-8, the context of the hashtags is similar with entries such as \#appetizing, \#beautiful and \#fascinating. This is because, the image presented to the user is the same as the cakes served on the plate.

In Figure 7, both Cake 1 and Cake 2, have reduced number of positive hashtags. However, the number of positive hashtags for Cake 3 have increased significantly where many users complimented on the fascinating colours and as well as the overall beauty of the cake. It also seemed that Cake 2 did not receive many hashtags implying that the cake appearance is still not favoured by the users. We find that in terms of appearance, digital images may be able to create a more positive perception if many colours are present and are striking. As Cake 3 received more positive hashtags after user tasted the cake, we interpreted that this is because users could see the cakes in a much closer view (close-up) and better appreciate the design. Therefore, digital images presented on a digital platform (i.e. mobile sites or websites) should allow zooming, panning and viewing from various angle to mimic the form of interactivity usually present when eating a cake through single or multi-finger gestures [28]. Such technology can lead to a more realistic judgment of the product judgments [29] and has been found to facilitate a positive impact on fulfilling users' hedonic needs and consumer digital experience [30-32]. 
b. Flavour

It was found that after users tasted the cake, users have created flavour-dimension hashtags describing taste (49\%) and sensation (51\%) attributes as illustrated in Figure 8. Figure 8 also implied that digital image alone would not do much justice on taste perception of the cakes. Cakes that were initially perceived as tasty and present positive sensation, had more negative-based hashtags and lesser positive hashtags input after user tasted the cakes.

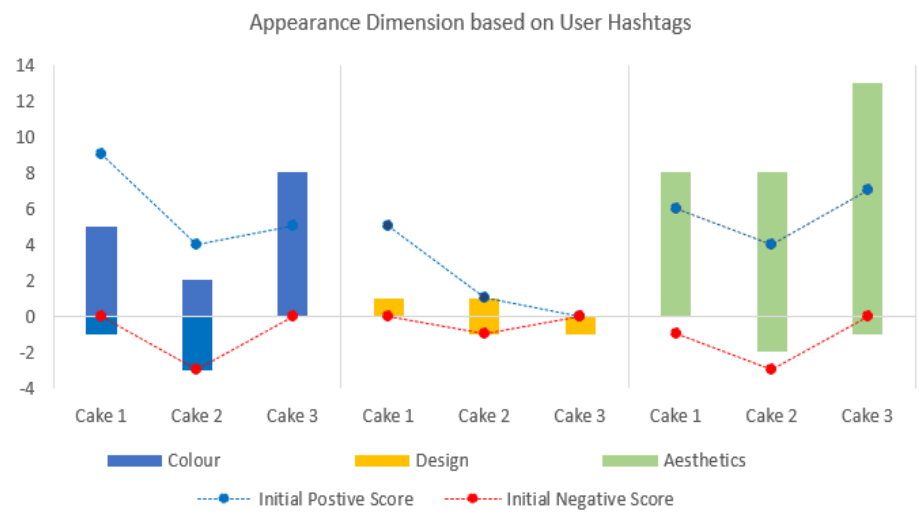

Figure 7. User hashtags on cake appearance based on true form

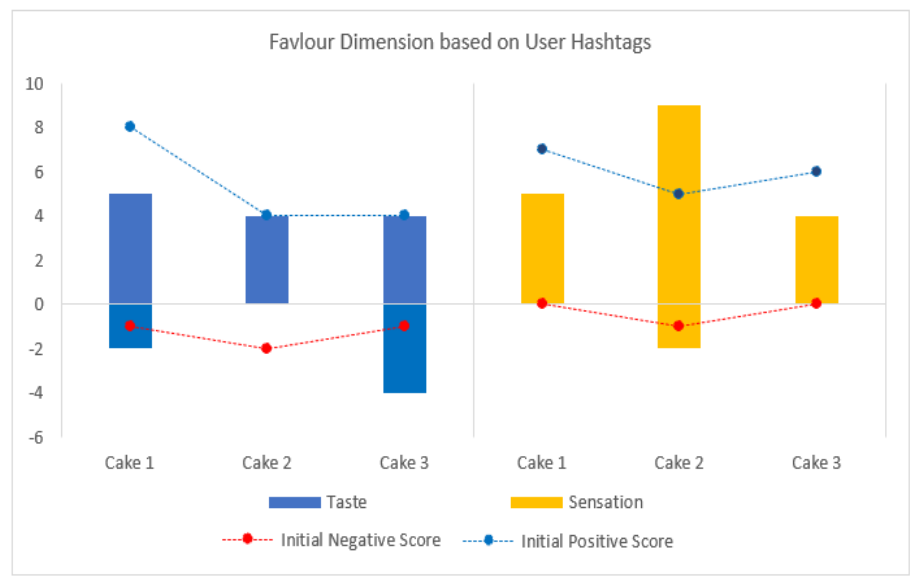

Figure 8. User hashtags on cake flavour based on true form

Cake 2 which was perceived as unappetizing now had more favourable hashtags in terms of sensation. This imply that plain looking cakes may taste more delectable than cakes that are striking and colourful. The unfavaourable perception user had based on digital images alone may be due to reasoning biases as they made conclusions based on experience even though they were presented with very limited evidence [33,34]. This puts a question to how digital images should be presented so that users are not overly influenced by appearance alone when judging the taste of the cake. The use of video showcasing an actor savouring the cake may be able to persuade users on the favourable taste of the cake $[25,35,36]$. Users would be able to see the actor's facial expression of sweet, buttery and delectable hence helping in making better judgement. c. Texture

In terms of food texture, the context of hashtags created by users in Study A and Study B did not have much difference, with $63 \%$ hashtags found on composition, $27 \%$ hashtags found on integration/disintegration and $10 \%$ on ingredients. Lesser positive hashtags were created for Cake 1 and Cake 3 in describing the cake compositions, but the opposite was observed for Cake 2. This is illustrated in Figure 9. 


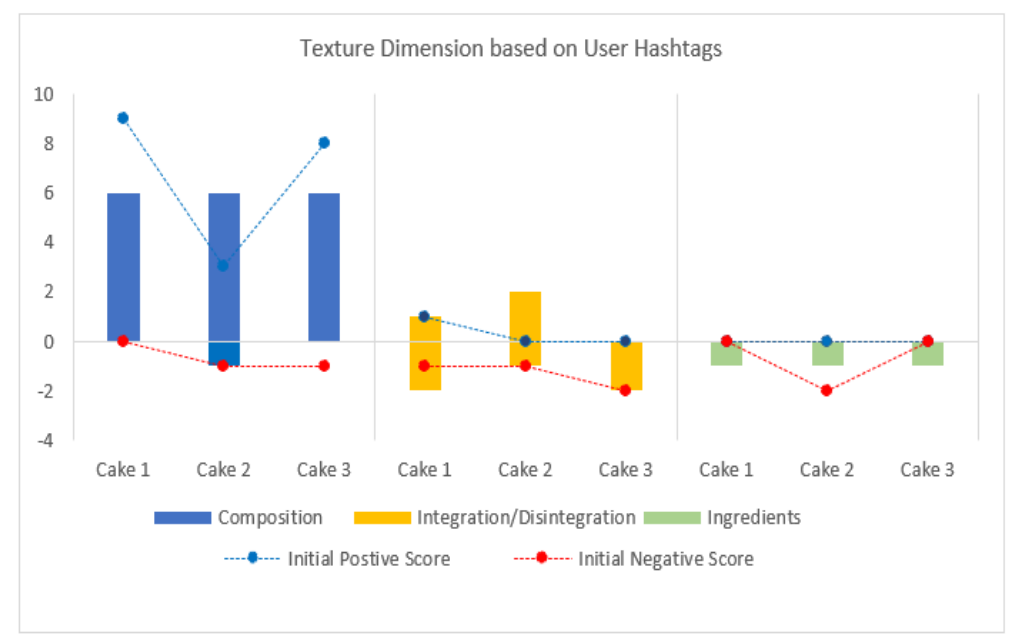

Cake 2 continued to have a more favourable hashtags in terms of integration/disintegration attribute where users found it \#soft and \#smooth. All cakes have negative hashtags for ingredient-based texture dimension where they said the cakes were oily and greasy. We believe that the perceptions made on the composition attribute in Study A were mostly based on experience-users have tapped into their previous cake eating experience and have assumed the cake to be soft and firm. However, after tasting the cake, they may have come to the realization that the texture is not as perceived.

Also, the greasiness or stickiness of a cake may not be easily visualized in the digital image. Therefore, additional visual indication ought to be in place so users could make a better perception of food texture. For example, to illustrate the smooth composition of the cake, we could show the cake mixing process where users could see how the final batter would look like. Additionally, in illustrating the integration of the cake, we could provide a video of cake slicing or scooping the cake with a spoon so users could see how crumbly or firm the cake when force is put upon it [27]. Finally, to show greasiness of the cake, the digital media could show an actor rubbing fingers together after touching the cake as indication of greasiness.

d. Hedonic

Figure 10 illustrates that not much change of hedonic type hashtags can be seen when comparing the numbers of hashtags between Study A and Study B. However, Cake 2 again has made a significant improvement in Study B in terms of hashtag attributes as it received even lesser negative hashtags and more positive hashtag attributes when compared with previous entry (Study A). To emphasis again, hedonic expressions represent an overall collective of all food dimensions as per Table 1 . The hedonic expressions for Cake 1 seemed to remain the same in this study while for Cake 3 it has reduced. Moreover, it was found that hashtags such as \#drooling, \#wantotry, \#perfect were revised into \#typical, \#contra and \#nomore. This would imply that colourful cakes perceived as vibrant and flavoursome through a digital image, may not present a pleasurable experience when it is consumed.

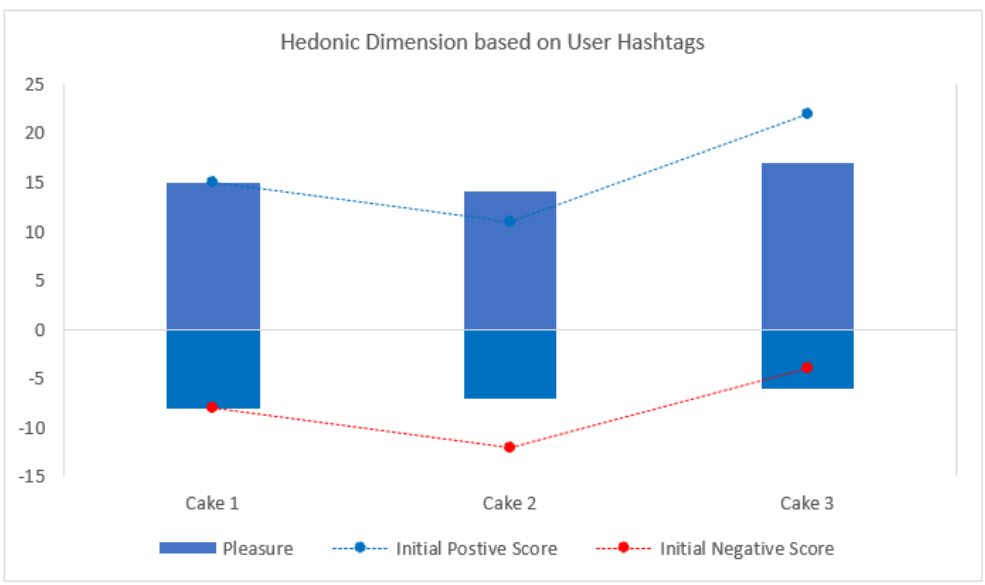

Figure 10. User hashtags on cake texture based on true form 
This post a question to how best we should present food via digital media that appears genuine and appealing so users' eating experience would meet or exceed their initial perception/expectation rather than the opposite. This may be addressed by incorporating online design features that is user-centered with emphasis on visual aesthetics, usability, fidelity, and motion to capture user attention $[37,38]$ in the promotion of better perception making.

\section{CONCLUSION}

The study examined the difference of user perception on a cake's overall flavour using cake's digital image and its true form. The perception was analysed based on user hashtags created for each of the cakes in the dummy Instagram account. Findings from Study A imply that users largely share similar perception towards the 'appearance', 'flavour' and 'texture' with many perceiving Cake 1 and Cake 3 as appetizing and flavourful while Cake 2 as unappetizing and sour. In short, all of the users shared similar perception across all digital images of the cakes. We also found that most of the perception are inclined to biasness. Cake 2 which was perceived unfavourable had more favourable hashtags after users have tasted it. The opposite was observed for Cake 1 and Cake 3. In short, digital images may not be able to facilitate an accurate perception of taste. Despite the letdown, it has helped us to identify actions that can be undertaken to facilitate better taste perception via digital image. This includes allowing image interactivity that mimics real object interaction, as well as providing richer media content such as video instead of just relying on static digital image. We acknowledge that the study setup does not project the reality of an Instagram post done in a natural setting. Usually, users would simply create hashtags without considering the categories as brought forth by this paper. Nevertheless, the setup which may seem very much simulated present a lens to how user make perception based on image and based on a food's true form. As a conclusion, visual cues can serve as sensory attributes allowing user to make informed perception on the food taste provided that a degree of user interactivity is adopted into the digital media.

\section{ACKNOWLEDGEMENTS}

The authors would like to express the gratitude to the Ministry of Higher Education, Malaysia and Universiti Teknologi MARA, Shah Alam, Selangor for the financial support given for this project (FGRS Grant) [File No: 600-IRMI/FRGS 5/3 (0007/2016)].

\section{REFERENCES}

[1] Y. Mejova, S. Abbar, and H. Haddadi. 2016. "Fetishizing food in digital age:\# foodporn around the world," in Tenth International AAAI Conference on Web and Social Media, 2016.

[2] Lee, E., Lee, J., Moon, J. and Sung, Y, "Pictures Speak Louder than Words: Motivations for Using Instagram," Cyberpsychology, Behavior, and Social Networking, vol. 18, no. 9, pp.552-556, 2015.

[3] Prada, M., Rodrigues, D., Garrido, M. and Lopes, J, "Food-pics-PT: Portuguese validation of food images in 10 subjective evaluative dimensions," Food Quality and Preference, vol. 61, pp.15-25, Oct 2017.

[4] Alhabash, S. and Ma, M., 2017. A Tale of Four Platforms: Motivations and Uses of Facebook, Twitter, Instagram, and Snapchat Among College Students?," Sage Journals, Feb 2017.

[5] Wong, I., Liu, D., Li, N., Wu, S., Lu, L. and Law, R, "Foodstagramming in the travel encounter," Tourism Management, vol. 71, pp. 99-115, April 2019.

[6] Zhao, S., Grasmuck, S. and Martin, J, "Identity construction on Facebook: Digital empowerment in anchored relationships," Computers in Human Behavior, vol. 24, no. 5, pp.1816-1836, Sep 2008.

[7] Ryan, T., Allen, K., Gray, D. and McInerney, D, "How Social Are Social Media? A Review of Online Social Behaviour and Connectedness," Journal of Relationships Research, vol. 8, 2017.

[8] Domahidi, E, "The Associations Between Online Media Use and Users' Perceived Social Resources: A MetaAnalysis," Journal of Computer-Mediated Communication, vol. 23, no. 4, pp.181-200, 2018.

[9] Rummo, P., Cassidy, O., Wells, I., Coffino, J. and Bragg, M, "Examining the Relationship between Youth-Targeted Food Marketing Expenditures and the Demographics of Social Media Followers," International Journal of Environmental Research and Public Health, vol. 17, no. 5, p.1631, March 2020.

[10] Usman, O. and Navari, R, "Influence of Promotion Through Social Media Instagram, Brand Awareness, Brand Equity, Brand Loyalty to Purchasing Decisions," SSRN Electronic Journal, Dec 2019.

[11] Okajima, K. and Spence, C, "Effects of Visual Food Texture on Taste Perception," i-Perception, vol. 2, no. 8, pp. 966-966, 2011.

[12] Gayler, T. and Sas, C. "An exploration of taste-emotion mappings from the perspective of food design practitioners" in Proceedings of the 2nd ACM SIGCHI International Workshop on Multisensory Approaches to Human-Food Interaction, pp. 23-28, 2017.

[13] Noel, C. and Dando, R, "The effect of emotional state on taste perception," Appetite, vol. 95, pp.89-95, Dec 2015. 
[14] Nishizawa, M., Jiang, W, and Okajima, K, "Projective-AR system for customizing the appearance and taste of food," in Proceedings of the 2016 workshop on Multimodal Virtual and Augmented Reality, no. 6, pp. 1-6, 2016.

[15] LI, D., LI, Y. and WU, R, "Consumer Aesthetic Experience in Product Design," Advances in Psychological Science, vol. 21, no. 2, pp.336-346, 2013.

[16] Feeney, E. and Hayes, J, "Exploring associations between taste perception, oral anatomy and polymorphisms in the carbonic anhydrase (gustin) gene CA6," Physiology \& Behavior, vol. 128, pp.148-154, April 2014.

[17] Mantonakis, A., Galiffi, B., Aysan, U., and Beckett, R, "The effects of the metacognitive cue of fluency on evaluations about taste perception," Psychology, vol. 4, no. 3, p. 318-324, 2013.

[18] Spence, C, "Background colour \& its impact on food perception \& behaviour," Food Quality and Preference, vol. 68, pp. 156-166, Sep 2018.

[19] Ariyasriwatana, W., and Quiroga, L. M, “A thousand ways to say'Delicious!'-Categorizing expressions of deliciousness from restaurant reviews on the social network site Yelp," Appetite, vol. 104, pp. 18-32, Sep 2016.

[20] Imram, N, "The role of visual cues in consumer perception and acceptance of a food product," Nutrition \& Food Science, vol. 99, no. 5, pp.224-230, 1999.

[21] Spence, C., Okajima, K., Cheok, A., Petit, O. and Michel, C, "Eating with our eyes: From visual hunger to digital satiation," Brain and Cognition, vol. 110, pp.53-63, Dec 2016.

[22] Chang, R. C. and Mak, A. H, "Understanding gastronomic image from tourists' perspective: A repertory grid approach," Tourism Management, vol. 68, pp. 89-100, Oct 2018.

[23] Papies, E. K, "Tempting food words activate eating simulations," Frontiers in Psychology, vol. 4, p.838, Nov 2013.

[24] Latip, H., Md Yusoff, I. and Hanapi, S, "Business in times of crisis: the story of Sarawak layered cake," Emerald Emerging Markets Case Studies, vol. 5, no. 7, pp.1-7, 2015.

[25] Harun, A., Ruslan, N., Suliman, S., Ismail, J., Baharin, H. and Noor, N, "We Who Eats: Understanding Food Perception upon First Sight," Journal of Image and Graphics, vol. 7, no. 2, pp. 39-44, 2019.

[26] Lucak, C. and Delwiche, J, "Efficacy of Various Palate Cleansers with Representative Foods," Chemosensory Perception, vol. 2, no. 1, pp. 32-39, Feb 2009.

[27] Conde-Petit, B, "Food texture and viscosity—concept and measurement," LWT-Food Science and Technology, vol. 36, no. 2, p. 281, 2003.

[28] Padilla S., Chantler M. J, "Shoogleit. com: Engaging online with interactive objects," Digital Engagement, 2011.

[29] Schlosser A. E," "Experiencing products in the virtual world: the role of goal and imagery in influencing attitudes versus purchase intentions," Journal of consumer research, vol. 1, no. 30, pp. 184-198, Sep 2003.

[30] Cai, L., He, X., Dai, Y. and Zhu, K., "Research on B2B2C E-commerce Website Design Based on User Experience," Journal of Physics: Conference Series, vol. 1087, p.062043, Sep 2018.

[31] Lee H. H, Kim J, Fiore A. M, "Affective and cognitive online shopping experience: Effects of image interactivity technology and experimenting with appearance," Clothing and textiles research Journal, vol. 28, no. 2, pp. 140-154, 2010.

[32] Teo H. H., Oh L. B., Liu C., and Wei, K. K, "An empirical study of the effects of interactivity on web user attitude," International journal of human-computer studies, vol. 58, no. 3, pp. 281-305, March 2003.

[33] Evans J. S, "Reasoning, biases and dual processes: The lasting impact of Wason (1960)," The Quarterly Journal of Experimental Psychology, vol. 69, no. 10, pp. 2076-2092, Oct 2016.

[34] Partos, T., Cropper, S. and Rawlings, D, "You Don't See What I See: Individual Differences in the Perception of Meaning from Visual Stimuli," PLOS ONE, vol. 11, no. 3, p.e0150615, March 2016.

[35] Harun, A., Ismail, J., Shiang, H., Noor, N., Baharin, H. and Suliman, S, “An exploratory study in conceptualizing user view on digital taste using design thinking. Indonesian," Internatonal Journal of Electrical Engineering and Computer Science IJEECS, vol. 17, no. 1, pp. 379-388, 2020.

[36] Jamaluddin, N. D. B., Adnan, W. A. W., Noordin, N., Noor, N. L. M., \& Suhaimi, A. I. H, "Towards Understanding the Concept of Tourism Experience Sharing," In International Conference on User Science and Engineering, Springer, Singapore, pp. 59-68, July 2018.

[37] Lee, W. and Benbasat, I, "Designing an electronic commerce interface: attention and product memory as elicited by web design," Electronic Commerce Research and Applications, vol. 2, no. 3, pp.240-253, 2003.

[38] Sanchez-Franco, M. and Rondan-Cataluña, F, "Virtual travel communities and customer loyalty: Customer purchase involvement and web site design," Electronic Commerce Research and Applications, vol. 9, no. 2, pp.171-182, 2010. 